\title{
MENTAL HEALTH EVALUATION OF MEDICINE GRADUATE STUDENTS THROUGHDASS-21DURING THEIR PARTICIPATION AT MARIO PINOTTI II STUDY AND THE COVID-19 PANDEMIC
}

Aline Rizzo Borges ${ }^{1, \star}$, João Vítor Ziroldo Lopes², Samuel Elias Basualto Dias ${ }^{3}$, Mirhelen Mendes Abreu4, Cleandro Pires Albuquerque ${ }^{5}$, Ana Beatriz Bacchiega ${ }^{6}$, Blanca Bica ${ }^{4}$, Danielle Christinne Soares Egypto Brito ${ }^{7}$, Débora Cerqueira Calderaro ${ }^{8}$, Ângela Luzia Branco Pinto Duarte ${ }^{9}$, Paula Reale Fernandes ${ }^{10}$, Gilda Aparecida Ferreira ${ }^{8}$, Kirla Wagner Poti Gomes ${ }^{11}$, Ana Karla Guedes $^{7}$, Bárbara Stadler Kahlow ${ }^{12}$, Evandro Mendes Klumb ${ }^{13}$, Claudia Diniz Lopes Marques ${ }^{9}$, Licia Maria Henrique Mota ${ }^{5}$, Gabriela Araújo Munhoz ${ }^{14}$, Eduardo dos Santos Paiva ${ }^{15}$, Helena Lucia Alves Pereira ${ }^{3}$, Gecilmara Salviato Pileggi ${ }^{6}$, Marcelo Medeiros Pinheiro ${ }^{16}$, José Roberto Provenza ${ }^{17}$, Ana Paula Monteiro Gomides ${ }^{5}$, Edgard Torres Reis-Neto ${ }^{16}$, Sandra Lucia Euzébio Ribeiro ${ }^{3}$, Emília Inoue Sato ${ }^{16}$, Thelma Skare ${ }^{12}$, Viviane Angelina de Souza ${ }^{10}$, Valeria Valim ${ }^{18}$, Adriana Maria Kakehasi ${ }^{8}$, Maycoln Leôni Martins Teodoro ${ }^{8}$, Lilian David de Azevedo Valadares ${ }^{9}$, Henrique de Ataíde Mariz ${ }^{9}$, Nafice Costa Araújo ${ }^{19}$

1.Centro Universitário de Brasília, Brasília (DF), Brazil. 2. Faculdade de Medicina da Universidade de São Paulo, São Paulo (SP), Brazil. 3.Universidade Federal do Amazonas, Manaus (AM), Brazil. 4.Universidade Federal do Rio de Janeiro, Rio de Janeiro (RJ), Brazil. 5.Universidade de Brasília, Brasília (DF), Brazil. 6.Faculdade de Medicina de Barretos, Barretos (SP), Brazil. 7.Universidade Federal da Paraíba, João Pessoa (PB), Brazil. 8.Universidade Federal de Minas Gerais, Belo Horizonte (MG), Brazil. 9.Universidade Federal de Pernambuco, Recife (PE), Brazil. 10.Universidade Federal de Juiz de Fora, Juiz de Fora (MG), Brazil. 11.Hospital Geral de Fortaleza, Fortaleza (CE), Brazil. 12.Hospital Universitário Evangélico Mackenzie, Curitiba (PR), Brazil. 13.Universidade do Estado do Rio de Janeiro, Rio de Janeiro (RJ), Brazil. 14.Irmandade da Santa Casa de Misericórdia de São Paulo, São Paulo (SP), Brazil. 15.Universidade Federal do Paraná, Curitiba (PR), Brazil. 16.Universidade Federal de São Paulo, São Paulo (SP), Brazil. 17.Pontifícia Universidade Católica de Campinas, Campinas (SP), Brazil. 18.Universidade Federal do Espírito Santo, Vitória (ES), Brazil. 19.Hospital do Servidor Público Estadual de São Paulo, São Paulo (SP), Brazil.

*Corresponding author: aline_rizzo_borges@hotmail.com

\section{BACKGROUND}

The coronavirus disease 2019 (COVID-19) pandemic has caused restrictive measures, including suspension of face-to-face lectures, clerkship and internship in medical schools. Additionally, medical students were invited to participate on the front-lines against the COVID19, which may have had negative impacts on students' mental health. The Mario Pinotti II study (MPII) is a multicenter study carried out to evaluate if hydroxychloroquine could have some protective role regarding moderate-severe forms of SARS-CoV-2 infection in patients with rheumatic diseases. Medical students were trained as voluntary evaluators to collect patient data during 24 weeks of follow-up. The aim of this study is to evaluate the effect of participation in MPII on medical students' mental health.

\section{MATERIALS AND METHODS}

This is a cross-sectional web survey designed to evaluate medical students participating in MPII, assigned as the volunteer group (VG), and their colleagues who were not involved in this project (control group [CG]), matched by sex and medical school (public and private background). The questionnaire was developed by the researchers and addressed demographic data, lifestyle habits, and participants' opinions about the MPII and the impact of the COVID-19 pandemic on their medical training routine. The domains of depression, anxiety and stress were assessed using the Brazilian version of the Depression, Anxiety and Stress Scale (DASS-21), which scores estimate the risk for mental suffering. Data collection was carried out from 20th July to 31st August 2020. The SPSS version 20.0 statistical package was used in all analyzes and a p-value of less than 0.05 was considered statistically significant.

\section{RESULTS}

A total of 684 medical students were included in our sample, 228 as VG and 456 as CG. Median age was 23 years (IQ 21-24) and the CG were older than the VG $(p<0.03)$. The majority of them were white ( $69 \%$, self-reported), women (63\%) and single marital status $(97 \%)$. There was no significant difference regarding comorbidities, ethnicity, smoking status, alcohol use, physical activity and self-reported previous anxiety and depression. The DASS-21 scores presented significantly lower values in VG 12(0-56) than CG 15(0-61) ( $p=0.001)$.

\section{CONCLUSION}

The participation of medical students in MPII study allowed social interaction with patients, colleagues, professors and medical assistants during COVID-19 pandemic, favoring higher inter-person engagement and better mental health status. 